[3] Yamauchi, Y., Mammoto, A., Dohi, M., Ebata, H., Morita, M. (2005). A Calculation Method for Predicting Heat and Smoke Detector's Response. Fire Science and Technology, 24 (4), 179-210. doi: https:// doi.org/10.3210/fst.24.179

[4] Nam, S. (2006). Predicting response times of fixed-temperature, rate-of-rise, and rate-compensated heat detectors by utilizing thermal response time index. Fire Safety Journal, 41 (8), 616-627. doi: https:// doi.org/10.1016/j.firesaf.2006.06.004

[5] Qiang, L. (2011). Estimation of Fire Detection Time. Procedia Engineering, 11, 233-241. doi: https:// doi.org/10.1016/j.proeng.2011.04.652

[6] Gottuk, D. T., Pomeroy, A. T. (2011). Heat Detector RTI - New Developments, Fire Suppression and Detection Research and Applications - A Technical Working Conference, Orlando, Florida.

[7] Pomeroy, A. T. (2010).Analysis of the effects of temperature and velocity on the response time index of heat detectors. Available at: https://drum.lib.umd.edu/bitstream/handle/1903/10492/Pomeroy umd_0117N_11368.pdf?sequence=1

[8] Park, H.-W., Cho, J.-H., Mun, S.-Y., Park, C.-H., Hwang, C.-H., Kim, S.-C., Nam, D.-G. (2014). Measurement of the Device Properties of Fixed Temperature Heat Detectors for the Fire Modeling. Fire Science and Engineering, 28 (1), 37-43. doi: https://doi.org/10.7731/kifse.2014.28.1.037

[9] Abramov, Yu. O., Kalchenko, Ya. Yu. (2018). Pat. No. 125948 UA. Sposib vyprobuvan teplovykh pozhezhnykh spovishchuvachiv. MPK G08B 17/06. No. u201800548; declareted: 19.01.2018; published: 25.05.2018, Bul. No. 10.

[10] Kalchenko, Ya. Yu., Abramov, Yu. O., Sobyna, V. O. (2016). Pat. No. 111447 UA. Sposib vyznachennia dynamichnykh kharakterystyk teplovykh pozhezhnykh spovishchuvachiv. MPK G08B 29/00. No. u201604945; declareted: 04.05.2016; published: 10.11.2016, Bul. No. 21.

\title{
DEVELOPMENT OF A METHOD FOR DETERMINING THE OPTIMAL CONTROL TRAJECTORY FOR THE PERIODIC PROCESSES
}

\author{
Igor Lutsenko \\ Department of Automation and Information Systems \\ Kremenchuk Mykhailo Ostrohradskyi National University \\ 20 Pershotravneva str., Kremenchuk, Ukraine, 39600 \\ morev.igor11@gmail.com \\ Anatolii Oksanych \\ Department of Automation and Information Systems \\ Kremenchuk Mykhailo Ostrohradskyi National University \\ 20 Pershotravneva str., Kremenchuk, Ukraine, 39600 \\ oksirena2017@gmail.com \\ Olena Fomovskaya \\ Department of Electronic Devices \\ Kremenchuk Mykhailo Ostrohradskyi National University \\ 20 Pershotravneva str., Kremenchuk, Ukraine, 39600 \\ 2fill.fo@gmail.com \\ Iryna Oksanych \\ Department of Automation and Information Systems \\ Kremenchuk Mykhailo Ostrohradskyi National University \\ 20 Pershotravneva str., Kremenchuk, Ukraine, 39600 \\ oksirena2017@gmail.com
}




\author{
Denis Mospan \\ Department of Electronic Devices \\ Kremenchuk Mykhailo Ostrohradskyi National University \\ 20 Pershotravneva str., Kremenchuk, Ukraine, 39600 \\ denis.mospan@gmail.com
}

Olga Serdiuk

Department of automation, computer science and technology

State institution of higher education «Kryvyi Rih National University»

11 Vitaliya Matusevycha str., Kryvyi Rih, Ukraine, 50027

olgajs28@gmail.com

\begin{abstract}
The development of new converting technologies and increasing the level of automation leads to an increase in the processing speed of available resources. This means that in case of inefficient or inefficient use of resources, the potential of economic advantage is lost, and the negative consequences of such losses can be identified too late.

In such conditions, the requirements for the selection of the criterion of optimization and the validity of the principles of optimal control increase. Moreover, the approach used may vary depending on the daily change in prices for energy products and fluctuations in the level of demand for manufactured products.

Despite the fact that such an approach seems obvious, today energy-intensive production suffers significant losses associated with the use of an inadequate model of technological operation, a subjective approach to the choice of optimization criterion and optimization method.

The task of developing a method for determining the optimal trajectory of managing energy-intensive industries with a changing level of demand for final products is posed. The solution to this problem consists of several stages. At the first stage, a model of a technological operation is being created, within the framework of which all significant factors affecting the decision result are taken into account. At the second stage, a global operation model is created, the input and output products of which are converted to comparable value values. At the third stage, the optimization criterion for the continuous operation of the system and the mode of incomplete use of its production capabilities is selected. At the final stage, the control path for intermittent and continuous modes of operation is determined.

Thus, the aim of research is development of a method for determining the optimal control trajectory in systems of energy-intensive systems, depending on the level of demand for the final product.

Keywords: optimal control trajectory, optimal control criterion, demand level control.

\title{
1. Introduction
}

In order to really optimize the technological process, it is necessary to work with a system-based model of the technological operation. Also, it is necessary to ensure the required quality of the main technological product, take into account the intensity of consumer demand, use a reasonable optimization criterion [1-3] and implement a system-based optimal control law [4-6].

To illustrate the proposed method, let's consider the steps to solve the scientific problem by the example of the technological process of batch heating of a salt solution of a fluid to a predetermined temperature using an electric heater.

Such a process is chosen as an illustration in view of the simplicity of its mathematical model, which makes it possible to reproduce all the research results, as well as due to the fact that the heating process is an inertial technological process. In addition, batch heating of a fluid, unlike continuous heating, does not require the use or simulation of transients, which also simplifies the illustration of the method.

The current value of the temperature of the fluid during the heating process can be determined using a known model [7]. 


$$
\mathrm{T}_{\mathrm{c}}=\mathrm{T}_{\mathrm{c}-1}+\mathrm{dT}_{\mathrm{g}}-\mathrm{d} \mathrm{T}_{\mathrm{d}}
$$

where $\mathrm{T}_{\mathrm{c}}$ - current temperature value; $\mathrm{T}_{\mathrm{c}-1}$ - previous temperature value; $\mathrm{dT}_{\mathrm{g}}-$ temperature increase; $\mathrm{dT}_{\mathrm{d}}$ - temperature decrease.

In turn,

$$
\mathrm{dT}_{\mathrm{g}}=\frac{\left(\mathrm{U}^{2} / \mathrm{R}\right) \cdot \mathrm{dt}+\mathrm{T}_{\mathrm{E}}}{\mathrm{c}_{\mathrm{v}} \mathrm{m}_{\mathrm{v}}+\mathrm{c}_{\mathrm{w}} \mathrm{m}_{\mathrm{w}}}, \quad \mathrm{dT}_{\mathrm{d}}=\frac{\eta \cdot \mathrm{s}\left(\mathrm{T}_{\mathrm{c}}-\mathrm{T}_{\mathrm{E}}\right) \mathrm{dt}}{\mathrm{c}_{\mathrm{v}} \mathrm{m}_{\mathrm{v}} \mathrm{d}_{\mathrm{v}}},
$$

where $U$ - voltage applied to the electric heater; $R$ - active resistance of the heater; $T_{E}-$ ambient temperature; $c_{v}$-tank heat capacity; $c_{w}$ - heat capacity of the fluid; $m_{w}$ fluid mass; $\eta$ - thermal conductivity of the environment; $s$ - area of the walls of the tank; $d_{v}-\operatorname{tank}$ wall thickness.

Using the expression (1) allows to construct a temperature model of the process of heating a fluid depending on the magnitude of the voltage applied to the heater (Fig. 1).

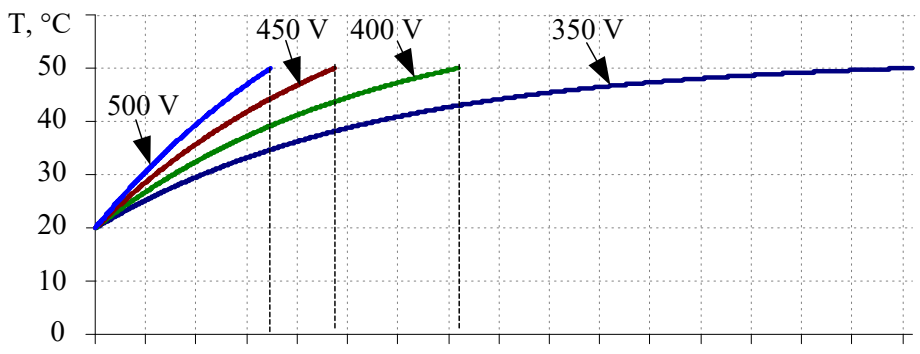

$\begin{array}{lllllllllllllllll}0 & 0,3 & 0,7 & 1,0 & 1,3 & 1,7 & 2,0 & 2,3 & 2,7 & 3,0 & 3,3 & 3,7 & 4,0 & 4,3 & 4,7 & 5,0 & t, h\end{array}$

Fig. 1. Change of temperature model of fluid heating from control

The task is not only to get a useful output product. Achieving the required quality is possible with different controls. In order to achieve the required quality, it is necessary to choose a control in which the available resources are used as efficiently as possible.

This approach involves working with such a model of the operational process, which allows to take into account the influence of all significant factors.

Model (1) is a model of a batch heating system for a fluid from an electric heater (Fig. 2).

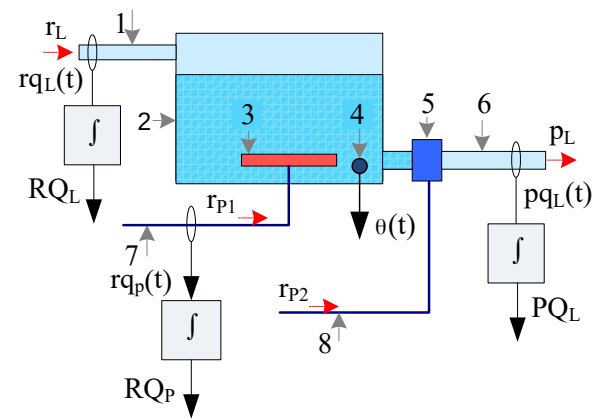

Fig. 2. Model of a batch fluid heating system: 1 - fluid supply channel; 2 - heater capacity;

3 - electric heater; 4 - temperature sensor; 5 - mechanism for dispensing heated fluid;

6 - channel for dispensing heated fluid; 7 - electricity supply for heating the fluid; 8 - electricity supply for dispensing a fluid; $r_{L}-$ inlet fluid flow; $r_{p 1}$ - energy of heating; $r_{p 2}$ - energy of issue;

$\mathrm{p}_{\mathrm{L}}$ - output fluid flow; $\theta(\mathrm{t})$ - current value of the heating temperature of the fluid

Here $\mathrm{rq}_{\mathrm{L}}(\mathrm{t})$ - recording signal of the input fluid flow; $\mathrm{rq}_{\mathrm{P} 1}(\mathrm{t})$ - registration signal of the flow of heating energy; $\mathrm{pq}_{\mathrm{L}}(\mathrm{t})$ - registration signal of the output flow of the heated fluid. Wherein 


$$
\mathrm{RQ}_{\mathrm{L}}=\int_{0}^{\mathrm{t}_{\mathrm{F}}} \mathrm{rq}_{\mathrm{L}}(\mathrm{t}) \mathrm{dt} ; \mathrm{RQ}_{\mathrm{P} 1}=\int_{0}^{\mathrm{t}_{\mathrm{F}}} \mathrm{rq}_{\mathrm{P} 1}(\mathrm{t}) \mathrm{dt} ; \mathrm{PQ}_{\mathrm{L}}=\int_{0}^{\mathrm{t}_{\mathrm{F}}} \mathrm{pq}_{\mathrm{L}}(\mathrm{t}) \mathrm{dt},
$$

where $t_{F}-$ moment of completion of the heating operation.

Since the volume of the heated fluid does not change from operation to operation, the output energy of the heated fluid $\left(\mathrm{r}_{\mathrm{P} 2}\right)$ can be neglected.

The parameters $R Q_{P 1}$ and $t_{L}$ will be influenced by the design features of the capacity for heating, the physical characteristics of the material of the container and the heated fluid. However, these features will not change the overall trends in energy consumption and operation time from control.

The construction of the dependence of energy consumption and the time of the heating operation on control shows that the amount of energy consumption decreases with an increase in productivity (Fig. 3).

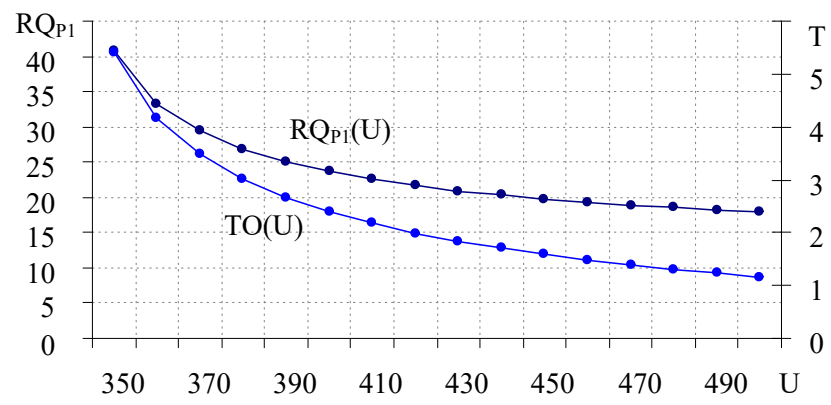

Fig. 3. Change of energy consumption and time of the heating operation from the control

Thus, using the data of the model in Fig. 2 for decision-making, it is possible to conclude that control with the maximum permissible level of supply voltage is most advantageous.

Obviously, this is not the case, since with an increase in the voltage level, the wear of the electric heater increases disproportionately. It also means that for making informed decisions, the data of model (1) is not enough. And this model requires consideration of the wear of the electric heater.

Determination of the amount of wear of the heater, during the technological operation, can be determined from the expression [8]

$$
\mathrm{T}=\mathrm{T}_{\mathrm{n}} \mathrm{k}_{\mathrm{u}}^{-\alpha}
$$

where $\mathrm{T}$ - service life of the electric heater; $T_{n}-$ the number of hours of operation at rated voltage; $\mathrm{k}_{\mathrm{u}}$ - the ratio of the actual voltage to the nominal value; $\alpha$-indicator of change in the average service life of an electric heater (for electric heaters).

Fig. 4 shows timing diagrams of changes in power consumption and wear of the electric heater from control.

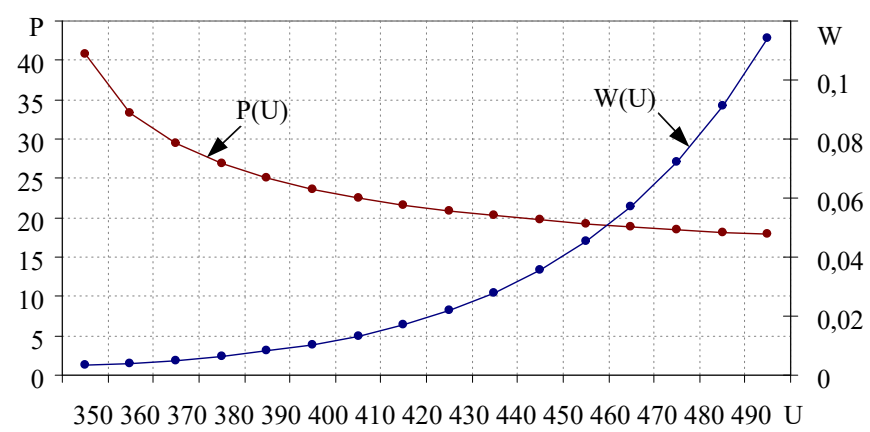

Fig. 4. Timing diagrams of changes in power consumption and wear of the electric heater from control 
Analysis of Fig. 3, 4 shows that it is impossible to express a judgment on the effectiveness of control without taking into account the wear of the heater (heating system in general).

In turn, this means that the solution of the optimization problem requires the study of a heating operation, where the heating system is one of the input products of the operation (Fig. 5).

Here (Fig. 5, a) cold fluid enters the input of the operation, electricity and the heating system itself. At the output of the operation, let's obtain a heated fluid and a more worn heating system.

The difference in the resource of the system during the operation and the output of the operation is equivalent to its wear $r_{w}$. Therefore, the model of the heating operation can be represented in the form of an equivalent model (Fig. 5, b).

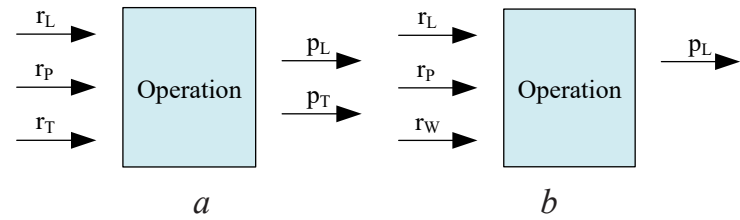

Fig. 5. The model of the operational heating process: $a$-using the valuation of equipment at the inlet and outlet of the operation; $b$ - using equipment wear as an input to the operation; $\mathrm{r}_{\mathrm{L}}-$ cold fluid; $r_{\mathrm{P}}$ - electricity; $\mathrm{r}_{\mathrm{T}}$ - entrance heating system; $\mathrm{p}_{\mathrm{L}}$ - heated fluid; $\mathrm{p}_{\mathrm{T}}$ - output heating system; $r_{W}$ - wear of the heating system during the operation

Thus, in the tasks of optimization of conversion processes, in particular in the problem of heating a fluid, the input products of the operation are fluid (product of directed influence), electric power (energy product) and wear of the electric heater (functional system).

\section{Development of a method for constructing optimal control trajectories in a changing demand}

In order to make a judgment about the effectiveness of the operation, its input and output products must be reduced to comparable value values (Fig. 6).

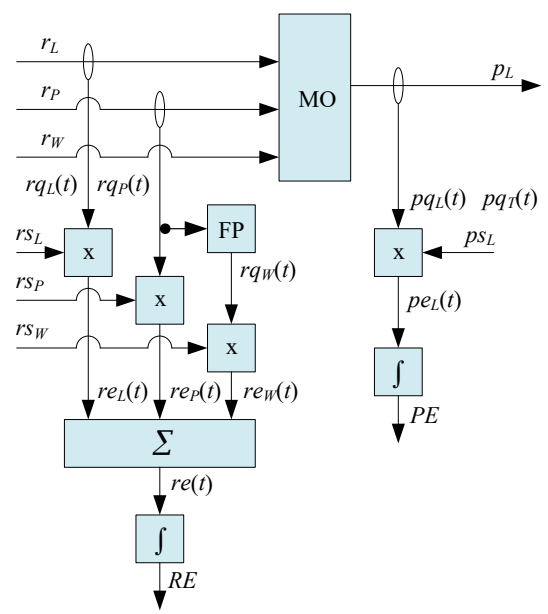

Fig. 6. Reduction of quantitative parameters of technological and energy products to comparable cost values: $\mathrm{MO}$ - operation model; $\mathrm{FP}$ - functional transducer $\mathrm{r}_{\mathrm{L}}$ - cold fluid; $\mathrm{r}_{\mathrm{P}}$ - electricity; $\mathrm{r}_{\mathrm{T}}-$ entrance heating system; $\mathrm{p}_{\mathrm{L}}$ - heated fluid; $\mathrm{p}_{\mathrm{T}}$ - output heating system; $\mathrm{r}_{\mathrm{W}}$ - wear of the heating system during the operation; $\mathrm{rq}_{\mathrm{L}}(\mathrm{t})$-registration signal of the input fluid flow; $\mathrm{rq}_{\mathrm{P} 1}(\mathrm{t})$ - registration signal of the flow of heating energy; $\mathrm{rq}_{\mathrm{W}}(\mathrm{t})$ - model of the flow of wear of the heater; $\mathrm{pq}_{\mathrm{L}}(\mathrm{t})$ signal registration of the output flow of the heated fluid; $\mathrm{rs}_{\mathrm{L}}-$ valuation of a unit of cold fluid; $\mathrm{rs}_{\mathrm{P}}-$ valuation of the unit of the energy product; $\mathrm{rs}_{\mathrm{W}}$ - valuation of the unit of depreciation; $\mathrm{ps}_{\mathrm{L}}$ - valuation of the unit of the heated fluid; $\mathrm{re}_{\mathrm{L}}(\mathrm{t})$ - scaled flow of cold fluid in value terms; $\mathrm{re}_{\mathrm{P}}(\mathrm{t})$ - scaled energy product flow; $\mathrm{re}_{\mathrm{W}}(\mathrm{t})$ - scaled flow of wear; $\mathrm{ps}_{\mathrm{L}}$ - scaled flow of heated fluid; re $(\mathrm{t})$ - scaled input function in value terms; pe $(\mathrm{t})$ - scaled output function in value terms; RE - integral valuation of input products of the operation; $\mathrm{PE}$ - integral valuation of the output products of the operation 
Then, by varying the voltage level from operation to operation, one can obtain the dependence of the change in the valuation of the input products of the operation, the valuation of the output products of the operation on the control and the operation time (Fig. 7).

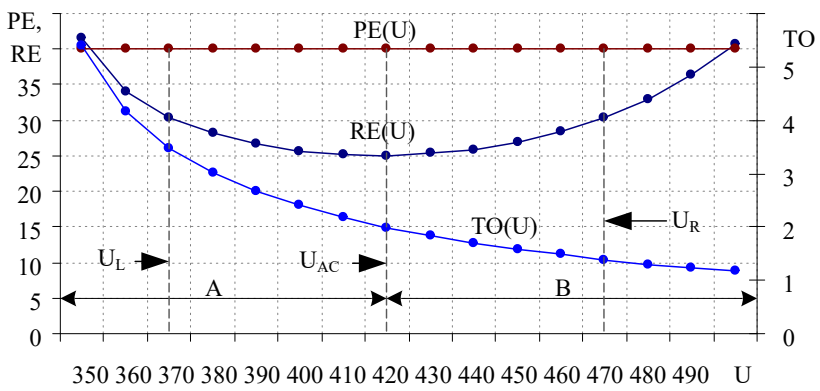

Fig. 7. Dependence of changes in the valuation of input products of the operation, valuation of output products of the operation on the control and time of the control operation

The study of dependencies shows that even without the use of special indicators, reliance on the three (RE, TO, PE) allows to express a judgment about the effectiveness of heating operations. Thus, in the control range A (Fig. 7), any operation with a large value of the control voltage is more efficient than an operation with a smaller value of the control voltage. This is due to the fact that in this control range, each subsequent operation has a lower value of RE and TO with equal PE.

On the other hand, it can be argued that the operation with the $\mathrm{U}_{\mathrm{R}}$ control is more efficient than the $\mathrm{U}_{\mathrm{L}}$ control, since with $\mathrm{RE}_{\mathrm{L}}=\mathrm{RE}_{\mathrm{R}}$ and $\mathrm{PE}=\mathrm{PE}_{\mathrm{R}}, \mathrm{TO}_{\mathrm{R}}<\mathrm{TO}_{\mathrm{L}}$.

In [9], an indicator of the form $E=f(R E, T O, P E)$ is developed, which is verified for the possibility of using it as an efficiency formula $[10,11]$. This expression has the form

$$
\mathrm{E}=\frac{(\mathrm{PE}-\mathrm{RE})^{2} \mathrm{TA}^{2}}{\mathrm{RE} \cdot \mathrm{PE} \cdot \mathrm{TO}}
$$

where TA - time to determine the potential effect of the operation. Moreover, TA is a unit time interval.

Using (3) allows to obtain a control in which $\mathrm{E}(\mathrm{U})$ reaches its maximum value (Fig. 8).

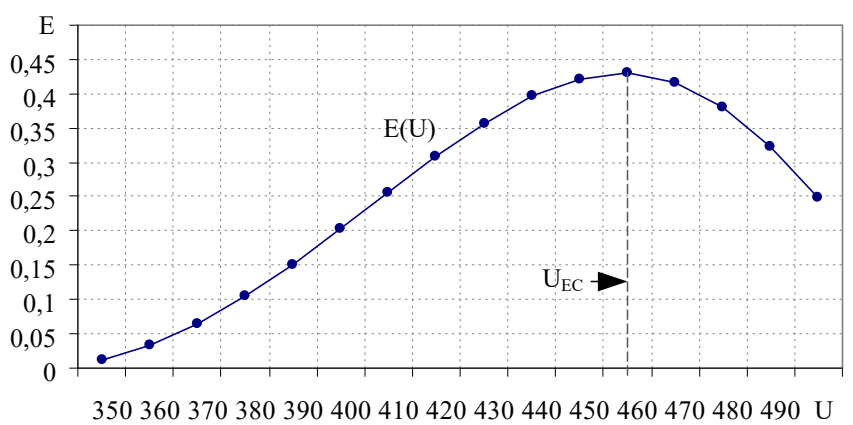

Fig. 8. Dependence of operation efficiency on control

As can be seen from Fig. 8, the maximum efficiency is achieved if $\mathrm{U}_{\mathrm{EC}}=460 \mathrm{~V}$ is supplied to the input of the heating system.

However, the use of $U_{\mathrm{EC}}$ controls leads to an increase in the financial capacity of the owner of the results of the operational process only if the demand for the output product of the heating system exceeds supply. Otherwise, production pauses make it inappropriate to operate the system while controlling $\mathrm{U}_{\mathrm{EC}}=460 \mathrm{~V}$, since the time gain is lost. In this situation, the maximum efficiency of resource use is achieved when working at the point of minimum cost (maximum value added) of the operation. In this case, this is the mode in which the voltage $U_{A C}=420 \mathrm{~V}$ is applied to the electric heater (Fig. 7, 9). 
Let's show it.

Let's assume that under conditions of reduced demand, heating operations follow with a time interval of 2 hours.

Let's suppose the heating system has completed the operation in $\mathrm{U}_{\mathrm{EC}}=460 \mathrm{~V}$. In this case, $\mathrm{RE}_{\mathrm{EC}}=28.33$ den. units, $\mathrm{TO}_{\mathrm{EC}}=1.48 \mathrm{~h}, \mathrm{PE}_{\mathrm{EC}}=40$ mon. units

Since the time interval between heating operations is $\mathrm{TO}=2 \mathrm{~h}$, then this interval will be the time of the operation. Then

$$
\mathrm{E}_{\mathrm{EC}}=\frac{\left(\mathrm{PE}_{\mathrm{EC}}-\mathrm{RE}_{\mathrm{EC}}\right)^{2} \mathrm{TA}_{\mathrm{EC}}{ }^{2}}{\mathrm{RE}_{\mathrm{EC}} \cdot \mathrm{PE}_{\mathrm{EC}} \cdot \mathrm{TO}^{2}}=\frac{(40-28.33)^{2} \cdot 1^{2}}{28.33 \cdot 40 \cdot 2^{2}}=0.03
$$

In the minimum cost mode $\left(\mathrm{U}_{\mathrm{AC}}=460\right)$, the operation indicators will be as follows: $\mathrm{RE}_{\mathrm{AC}}=$ $=25$ mon. unit; $\mathrm{TO}_{\mathrm{AC}}=1.99 \mathrm{~h} ; \mathrm{PE}_{\mathrm{AC}}=40$ mon. units Taking into account the time interval between heating operations $(\mathrm{TO}=2)$, let's obtain

$$
\mathrm{E}_{\mathrm{AC}}=\frac{\left(\mathrm{PE}_{\mathrm{AC}}-\mathrm{RE}_{\mathrm{AC}}\right)^{2} \mathrm{TA}_{\mathrm{AC}}{ }^{2}}{\mathrm{RE}_{\mathrm{AC}} \cdot \mathrm{PE}_{\mathrm{AC}} \cdot \mathrm{TO}^{2}}=\frac{(40-25)^{2} \cdot 1^{2}}{25 \cdot 40 \cdot 2^{2}}=0.056
$$

Thus, since in the case of reduced performance, RE and TO operations are the same, the "value" indicator can be used as a performance criterion.

Thus, the $\mathrm{U}_{\mathrm{AC}}$ control minimizes costs in the mode when the level of demand is less than the performance of the heating system in the $U_{E C}$ mode. On the other hand, the $U_{E C}$ control ensures the maximization of efficiency in the conditions when the level of demand exceeds the performance of the heating system in the $\mathrm{U}_{\mathrm{EC}}$ mode.

It should be noted that, until now, control meant setting the supply voltage, the value of which did not change during the operation. For example, the valuation of input products of the operation $\mathrm{RE}_{\mathrm{AC}}=25$ den. units and the time of operation $\mathrm{TO}=2$ hours (Fig. 7) were obtained when a voltage of $420 \mathrm{~V}$ was applied to the electric heater $\left(\mathrm{U}_{\mathrm{AC}}(\theta)=\right.$ const). The valuation of input products operations $\mathrm{RE}_{\mathrm{EC}}=28.33$ mon. units and the operation time $\mathrm{TO}=2 \mathrm{~h}$ (Fig. 7) were obtained with a voltage of $460 \mathrm{~V}$ applied to the electric heater $\left(\mathrm{U}_{\mathrm{EC}}(\theta)=\right.$ const $)$.

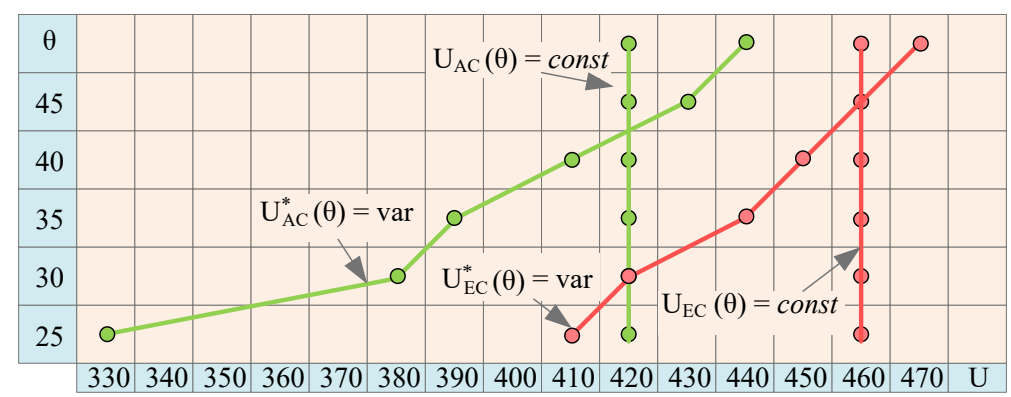

Fig. 9. Control trajectories at which the maximization of efficiency is achieved:

$\mathrm{U}_{\mathrm{AC}}(\theta), \mathrm{U}_{\mathrm{EC}}(\theta)$ - at constant control of temperature change; $\mathrm{U}_{\mathrm{AC}}^{*}(\theta), \mathrm{U}_{\mathrm{EC}}^{*}(\theta)$ - at control changes in temperature change function

At this approach, the control does not change as a function of the heating temperature. Therefore, in order to maximize the efficiency of resource use, it is necessary to determine how to change the control trajectory during heating.

In the course of the research, it was established that if setting different controls for the heating zone from 20 to $25^{\circ} \mathrm{C}$, then let's obtain that the minimum costs will be achieved by controlling $\mathrm{U}_{\mathrm{AC}}=330 \mathrm{~V}$. For the heating zone from 25 to $30^{\circ} \mathrm{C}$, the control that leads to the minimum costs will be $\mathrm{U}_{\mathrm{AC}}=380 \mathrm{~V}$.

Continuing the research, let's obtain the $\mathrm{U}_{\mathrm{AV}}(\theta)$ control trajectory at which the cost of heating the fluid will be $2.8 \%$ lower in relation to the $\mathrm{U}_{\mathrm{AC}}(\theta)$ control (Fig. 9). 
Similarly, the optimal control trajectory $\mathrm{U}_{\mathrm{EV}}(\theta)$ is obtained, which provides a higher $(0.4 \%)$ value of resource efficiency.

Since, with an increase in the heating temperature, the optimal control trajectory shifts to the right, the method of finding the optimal control consists in determining the initial value of the optimal trajectory. The next point of the trajectory is determined when moving to the next heating level by shifting the control to the right until the next extremum is determined.

\section{Discussion of the results of the development of a method for constructing optimal trajecto- ries in the conditions of changing demand} situation.

At present, in cybernetics, as the science of general principles of control, there is a difficult

Thus, it is believed that the existing control theory has already been established, and its methods allow to confidently solve most practical issues.

In reality, this is far from the case. Currently, there is no established definition of the concept of "control". There is no generally accepted definition of such fundamental concepts as "operation", "optimization", "functional system", "optimization criterion”.

It is for this reason that the task of determining the optimal control trajectory is considered sequentially - from the stage of building a model of the heating operation to determining the control trajectory as a function of temperature change.

Thus, it is shown that a model that does not take into account the wear factor will lead to guaranteed inefficient control.

The paper uses an operational approach and an optimization criterion in the form of an efficiency indicator. This is due to the fact that numerical methods that are currently widely used for solving optimization problems lead to results whose consequences are not systematically justified.

It is shown this using the intermediate research results.

Fig. 10 shows the results of a change in the cost estimates of the input products of the operation at different controls in the process of temperature change in increments of $5{ }^{\circ} \mathrm{C}$. method.

In this case, the choice of the minimum cost can't be done using the dynamic programming

Let's suppose that at the initial stage of heating a control was established in the form of a supplied voltage of $390 \mathrm{~V}$ (cell B1). In this case, the valuation of the input products of the operation will be $\mathrm{RE}_{\mathrm{B} 1}=2.576$ mon. units.

Change the control in the next step by setting the voltage to $380 \mathrm{~V}$. Get RE=5.403 mon. units.

If to change the temperature from 20 to $25^{\circ} \mathrm{C}$ it took 2,576 mon. units, then the following $5{ }^{\circ} \mathrm{C}$ required 5,403-2,576 $=2,827$ mon. units. Checking the coordinates of B2 and C2, respectively, let's obtain 2.84 mon. units and 2,881 mon. units.

That is, an attempt to achieve better control in the next step is doomed to failure, since the increment in the cost of the next heating stage is always higher than the previous step.

It can be assumed that this feature is inherent only in some systems, in particular, heating systems. However, the problems of using dynamic programming methods are much deeper.

\begin{tabular}{c}
\hline \multicolumn{2}{|c|}{ Coordinates } \\
\cline { 3 - 6 }
\end{tabular}

Fig. 10. Fragment of the research results of the influence of control on the valuation of input products of the operation 
Let's consider the possibility of comparing the effectiveness of operational processes based on operations of the type A and B by the method of dynamic programming (Fig. 11).

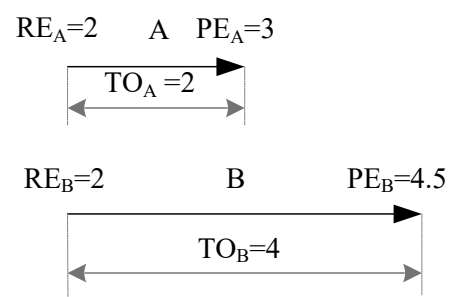

Fig. 11. Operations that have the same initial investment and the ability to compare the results of the operational process

It would seem that there are opportunities for such a comparison, $\mathrm{RE}_{\mathrm{A}}=\mathrm{RE}_{\mathrm{B}}$ and $\mathrm{TO}_{\mathrm{B}}=2 \mathrm{TO}_{\mathrm{A}}$. Since the value added ratio $(\mathrm{k})$ of an operation of the type $\mathrm{A}$ is equal to $\mathrm{k}_{\mathrm{A}}=\mathrm{PE}_{\mathrm{A}} /$ $\mathrm{RE}_{\mathrm{A}}=1.5$, the effectiveness of these operations can be assessed by the final result of the operational processes (Fig. 12).

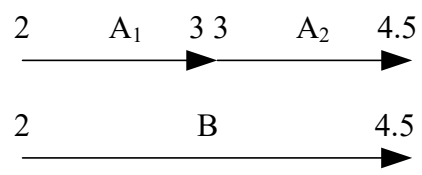

Fig. 12. Results of mathematical modeling of compared operations based on operational processes

Since the initial investments in operations are the same, the processes end at the same time and the final result is also the same, it is logical to assume that an operation of type $\mathrm{A}$ is equal in efficiency to an operation of type B.

However, it is not. An operational process based on operations of type A required a transfer of value from the output of operation $A_{1}$ to the input of operation $A_{2}$. Since such a transfer is impossible to accomplish without loss, operation B is more efficient than operation A.

In this case, in order to establish this fact, it is enough to compare the efficiency of operations using expression (1)

$$
\begin{gathered}
E_{A}=\frac{(3-2)^{2} \cdot 1^{2}}{2 \cdot 3 \cdot 2^{2}}=0.0417, \\
E_{B}=\frac{(4.5-2)^{2} \cdot 1^{2}}{2 \cdot 4.5 \cdot 4^{2}}=0.0434 .
\end{gathered}
$$

The performance criterion indicates the operation, the use of which in the operational process ensures that the owner of the results of the operational process is maximized.

This fact suggests that the results, to which the use of dynamic programming methods leads, oddly enough, have never been verified.

Of course, using it they tried to close the "gap" in the question of evaluating operations. If we pay attention, then in the discipline "research of operations" there is no model of the operation itself.

This method is based on the study of the operation model.

Is it possible to do without building a model of operation?

This can't be done.

In order to make judgments about efficiency, data is needed, on the quantitative parameters of the input and output products of the operation. Of course, the initial data can be obtained experi- 
mentally. But all further transformations of this data are nothing but the process of researching the model of operation.

Separately cost to stay on the optimization criteria.

Also for some reason it is considered that the optimization criterion is chosen by the system user at its discretion.

In fact, any system owner seeks to maximize their financial capabilities. In this sense, it does not need cost minimization, if an increase in costs of $1 \%$ leads to a decrease in operation time by half. Similarly, the owner of the results of the system process does not need to maximize profits, if the increase in profits twice leads to a fourfold increase in costs.

Similar reasoning can be given in relation to profitability, income, not to mention attempts to use technical indicators as an optimization criterion.

In such cases, it is possible to talk about extreme control, but not about optimal.

\section{Conclusions}

It is established that the determination of the optimal control trajectory with respect to the "hard control" allows to obtain higher quality results of the optimization process.

A method is proposed for determining the optimal control trajectory, each point of which can be obtained as a result of a search method, to the left of the previous point within its control horizon.

\section{References}

[1] Rodrigues, V. P., Pigosso, D. C. A., McAloone, T. C. (2016). Process-related key performance indicators for measuring sustainability performance of ecodesign implementation into product development. Journal of Cleaner Production, 139, 416-428. doi: https://doi.org/10.1016/j.jclepro.2016.08.046

[2] Gregory, J., Olivares, A., Staffetti, E. (2012). Energy-optimal trajectory planning for the Pendubot and the Acrobot. Optimal Control Applications and Methods, 34 (3), 275-295. doi: https://doi.org/10.1002/ oca. 2020

[3] Ju, B.-F., Bai, X., Chen, J., Ge, Y. (2013). Design of Optimal Fast Scanning Trajectory for the Mechanical Scanner of Measurement Instruments. Scanning, 36 (2), 185-193. doi: https://doi.org/10.1002/ sca. 21084

[4] Kulej, M. (2011). Operations research. Business Information Systems, 70.

[5] Grad, S.-M. (2016). Duality for Multiobjective Semidefinite Optimization Problems. Operations Research Proceedings 2014, 189-195. doi: https://doi.org/10.1007/978-3-319-28697-6_27

[6] Kasperski, A., Zieliński, P. (2016). Robust Discrete Optimization Problems with the WOWA Criterion. Operations Research Proceedings 2014, 271-277. doi: https://doi.org/10.1007/978-3-319-28697-6_38

[7] Amel'kin, V. V. (1987). Differencial'nye uravneniya v prilozheniyah. Moscow: Nauka, 160.

[8] Mihaylov, V. V. (1973) Nadezhnost' elektrosnabzheniya promyshlennyh predpriyatiy. Moscow: Energiya, 167.

[9] Lutsenko, I. (2016). Definition of efficiency indicator and study of its main function as an optimization criterion. Eastern-European Journal of Enterprise Technologies, 6 (2 (84)), 24-32. doi: https://oi. org/10.15587/1729-4061.2016.85453

[10] Lutsenko, I., Fomovskaya, O., Vihrova, E., Serdiuk, O., Fomovsky, F. (2018). Development of test operations with different duration in order to improve verification quality of effectiveness formula. Eastern-European Journal of Enterprise Technologies, 1 (4 (91)), 42-49. doi: https://doi.org/10.15587/17294061.2018.121810

[11] Lutsenko, I., Fomovskaya, O., Serdiuk, O., Baranovskaya, M., Fomovskyi, V. (2018). Development of test operations of different duration in terms of input for the verification of efficiency formula. Eastern-European Journal of Enterprise Technologies, 5 (4 (95)), 14-21. doi: https://doi.org/10.15587/17294061.2018.142212 